\title{
Two-year Follow-up of Volumetric-modulated Arc Therapy for Treating Internal Mammary Nodes in Locally Advanced Breast Cancer
}

\author{
YI-JUN KIM ${ }^{1}$, KYUBO KIM ${ }^{1}$, RENA LEE ${ }^{1}$, JIYOUNG KIM ${ }^{1}$, WONGUEN JUNG ${ }^{1}$, \\ NAM-SUN PAIK ${ }^{2}$, BYUNG-IN MOON ${ }^{2}$, WOOSUNG LIM ${ }^{2}$ and JIHAE LEE ${ }^{1}$ \\ Departments of ${ }^{1}$ Radiation Oncology, and ${ }^{2}$ Surgery, \\ Ewha Womans University Mokdong Hospital, Seoul, Republic of Korea
}

\begin{abstract}
Background/Aim: We evaluated dosimetric and clinical results of volumetric-modulated arc therapy (VMAT) treating internal mammary nodes (IMNs) in patients with locally advanced breast cancer. Patients and Methods: Between July 2012 and December 2013, treatment outcomes of 31 patients with stage III breast cancer treated with postoperative radiotherapy including the IMN field using VMAT were analyzed. Results: The median follow-up was 25.2 months. VMAT showed good homogeneity and improved conformity. The incidence of lung toxicity of grade 2 or more was $3.2 \%$, and cardiac toxicity was not observed. No patient developed local recurrence. Conclusion: VMAT appears safe for the treatment of locally advanced breast cancer including the IMN field.
\end{abstract}

After randomized trials showed no survival benefit from extended mastectomy including elective internal mammary node (IMN) dissection compared to mastectomy without IMN dissection $(1,2)$, IMN dissection has rarely been implemented even for patients who have metastases in their IMNs. Since then, radiotherapy (RT) has become the main treatment option for IMN in patients with breast cancer with or without involved IMNs (3).

However, including IMNs within the RT field tends to increase the dose to organs at risk (OAR) (4), hence minimizing the dose to normal organs and tissues while fulfilling the high homogeneity and conformity of treatment plans is a challenging goal. Since the development of Otto's volumetric-modulated arc therapy (VMAT) (5), many studies have attempted to apply VMAT to breast cancer treatment to

Correspondence to: Jihae Lee, MD, Department of Radiation Oncology, Ewha Women's University Mokdong Hospital, 1071 Anyangcheon-ro Yangcheon-gu, Seoul, 07985, Korea. Tel: +82 226505331, Fax: +82 226540363, e-mail: jihae.leee@gmail.com

Key Words: VMAT, breast cancer, internal mammary nodes. improve planning quality and to reduce doses to OAR. Previous studies reported that VMAT achieved better homogeneity and conformity than the conventional technique while the doses to OAR were variable depending on the organs and techniques (6-11). To our knowledge, there are no data reporting the clinical outcomes, including toxicities and local control, after VMAT in patients with breast cancer.

In this study, we retrospectively investigated patients with locally advanced breast cancer who were treated with VMAT including the IMN field following surgery and analyzed dosimetric results as well as clinical outcomes.

\section{Patients and Methods}

Patients. Between July 2012 and December 2013, 31 patients with stage III breast cancer treated with postoperative RT including the IMN field using VMAT were included. Eleven patients had metastases in IMNs and seven patients in supraclavicular nodes (SCNs). Every patient signed a written informed consent form before initiation of RT. This study was approved by the Institutional Review Board (EUMC 2015-08-007-001).

Target and OAR delineation and dose prescription. Gross target volumes (GTVs) were unresected metastatic nodes in SCNs or IMNs on pretreatment imaging. The clinical target volume (CTV) included the breast or chest wall, axillary lymph node level II/III, infraclavicular lymph nodes, SCNs and IMNs. IMNs above and at the level of involvement were included in the CTV or first to third intercostal space level for elective irradiation. Planning target volume (PTV) 1 and PTV 2 were generated by adding a 7-10 mm margin around the CTV and GTV respectively and PTV1 was adjusted according to the lung surface and was 3-5 $\mathrm{mm}$ inside the skin. The tumor bed was contoured based on surgical clips and scar.

Radiation of $50 \mathrm{~Gy}$ in 25 fractions was prescribed to the PTV1 and 60-70 Gy in 25 fractions to the PTV2 using the simultaneously integrated boost (SIB) technique. The dose constraints were V20 less than $35 \%$ for the ipsilateral lung and V25 less than $10 \%$ for the heart according to QUANTEC (12). Tumor bed boost was delivered with electron with dose of $10 \mathrm{~Gy}$ in five fractions separately after completion of VMAT in patients who underwent breast conserving surgery. 
Table I. Patient and tumor characteristics $(n=31)$.

\begin{tabular}{llc}
\hline Characteristic & & No. of patients \\
\hline Median age (range), years & & $48.3(31-71)$ \\
Menopause & Yes & 14 \\
Stage & No & 17 \\
& IIIA & 12 \\
Laterality & IIIB & 0 \\
Location of main mass & IIIC & 19 \\
& Right & 18 \\
& Left & 13 \\
& Upper outer & 10 \\
& Upper inner & 7 \\
Multifocality/multicentricity & Lower outer & 8 \\
\multirow{4}{*}{ Histologic grade } & Lower inner & 3 \\
& Center & 3 \\
& Yes & 14 \\
Lymph node involvement & No & 17 \\
& 1 & 2 \\
& 2 & 14 \\
Lymphovascular invasion & IMN+axilla & 15 \\
& SCN+axilla & 7 \\
& Axilla only & 13 \\
& Positive & 18 \\
& Negative & 13 \\
\hline
\end{tabular}

IMN: Internal mammary lymph node; SCN: supraclavicular lymph node.

VMAT planning. Eclipse ${ }^{\circledR} 10.0$ was used for planning. VMAT planning comprised three partial rotations (Arc1, Arc2, and Arc3). In cases involving the right breast, Arc 1 was counter-clockwise $(\mathrm{CCW})$ rotation $\left(60^{\circ}-230^{\circ}\right.$; field size $\left.\mathrm{x} 1=9 \mathrm{~cm}, \mathrm{x} 2=4 \mathrm{~cm}\right)$, Arc 2 was clockwise $(\mathrm{CW})$ rotation $\left(230^{\circ}-60^{\circ}\right.$; field size $\left.\mathrm{x} 1=4 \mathrm{~cm}, \mathrm{x} 2=9 \mathrm{~cm}\right)$, and $\mathrm{Arc} 3$ was the last $\mathrm{CCW}$ rotation with a full open field $\left(60^{\circ}-210^{\circ}\right.$; field size $x 1=9 \mathrm{~cm}, x 2=9 \mathrm{~cm}$ ). Corresponding opposite angles were used for left-sided breast cancer.

Dosimetric parameters. The homogeneity index (HI) and the conformity index $(\mathrm{CI})$ of the PTV1 were defined as follows: $\mathrm{HI}=$ $\left[\left(\mathrm{D}_{5 \%}-\mathrm{D}_{95 \%}\right) / \mathrm{D}_{p}\right] \times 100$, where $\mathrm{D}_{5 \%}$ and $\mathrm{D}_{95 \%}$ were the minimum doses delivered to $5 \%$ and $95 \%$ volume of the PTV, and Dp was the prescribed dose to the breast/chest wall (50 Gy); CI $=\left(\mathrm{V}_{95 \%} / \mathrm{PTV}\right)$ $\times 100$, where $\mathrm{V}_{95 \%}$ represented the volume receiving $95 \%$ of the prescribed dose.

Follow-up and toxicity evaluation. Patients were followed-up with breast examination and radiographs every 3 to 12 months according to clinical demand. The Radiation Therapy Oncology Group (RTOG) Acute Radiation Morbidity Scoring Criteria and RTOG/the European Organization for Research and Treatment of Cancer (EORTC) Late Radiation Morbidity Scoring Schema (13) were used to evaluate acute and late radiation toxicities, respectively.

Statistics. Dosimetric parameters were compared using Student's $t$-test. Kaplan-Meier estimates were used for estimating locoregional control. A $p$-value of less than 0.05 was considered statistically significant. All statistics were performed using the Statistical Package for the Social Sciences software (SPSS) version 18 (SPSS Inc., Chicago, IL, USA).
Table II. Treatments patients received $(n=31)$.

\begin{tabular}{lc}
\hline Treatment & No. of patients \\
\hline Surgery & \\
BCS & 13 \\
MRM & 18 \\
Chemotherapy & 2 \\
Adj CMF x 6 & 16 \\
Adj AC x 4, T x 4 & 9 \\
Neo AT x 6 & 2 \\
Neo AT x 3, Adj AT x 3 & 2 \\
None & \\
Hormonal therapy & 16 \\
Tamoxifen & 10 \\
Aromatase inhibitor & 5 \\
None & \\
Trastuzumab & 8 \\
Yes & 23 \\
No & \\
\hline
\end{tabular}

BCS: Breast-conserving surgery; MRM: modified radical mastectomy; CMF: cyclophosphamide + methotrexate + fluorouracil; AC: doxorubicin + cyclophosphamide; T: Taxol; Neo: neoadjuvant; Adj: adjuvant; Eqv: equivalent dose.

\section{Results}

The median follow-up was 25.2 months. The characteristics of the patients and treatments are shown in Tables I and II.

Dosimetric analysis. All dosimetric results are listed in Tables III and IV. Tumor laterality and surgery type did not influence HI. Patients with right-sided breast cancer or treated with breast-conserving surgery had a higher CI than those with left-sided breast cancer or modified radical mastectomy, but the differences were not statistically significant (Tables III and IV).

The average mean heart dose (MHD) in patients overall was 12.1 Gy. The average MHD of those with left-sided breast cancer was $14.3 \mathrm{~Gy}$, which was higher than for those with right-sided breast cancer (10.6 Gy, $p=0.005)$. For patients overall, the average mean lung dose (MLD) and V20 of ipsilateral lung were 19.2 Gy and $32.7 \%$, respectively, and mean dose to the contralateral breast was 5.7 Gy and V5 of contralateral breast was $46.7 \%$. No difference in dose to the ipsilateral lung and contralateral breast was found according to tumor laterality and surgery type (Tables III and IV).

Radiation toxicities. Table $\mathrm{V}$ shows the results of acute and late radiation toxicities. No patient experienced grade 2 or more acute lung toxicity. Among 11 patients (35.4\%) who showed radiological changes of the lung during the follow-up period, only one patient had grade 2 pulmonary effusion in the 
Table III. Comparison of dosimetric parameters according to tumor laterality.

\begin{tabular}{|c|c|c|c|c|}
\hline & $\begin{array}{c}\text { All } \\
(\mathrm{n}=31)\end{array}$ & $\begin{array}{l}\text { Right breast } \\
\quad(\mathrm{n}=18)\end{array}$ & $\begin{array}{l}\text { Left breast } \\
\qquad(\mathrm{n}=13)\end{array}$ & \\
\hline & & Mean $(95 \% \mathrm{CI})$ & & $p$-Value \\
\hline Homogeneity index & $17.4(9.0-31.6)$ & $17.1(9.0-31.6)$ & $17.7(10.8-31.1)$ & 0.759 \\
\hline Conformity index & $82.5(39.1-98.5)$ & $85.2(67.2-97.5)$ & $78.7(39.1-98.5)$ & 0.270 \\
\hline \multicolumn{5}{|l|}{ Heart } \\
\hline MHD (Gy) & $12.1(5.3-20.3)$ & $10.6(5.3-13.9)$ & $14.3(9.3-20.3)$ & 0.005 \\
\hline V10 (\%) & $48.6(6.3-98.4)$ & $42.3(6.3-70.0)$ & $57.4(22.6-98.4)$ & 0.824 \\
\hline V20 (\%) & $13.7(0.0-37.2)$ & $7.5(0.0-15.9)$ & $22.2(9.4-37.2)$ & 0.088 \\
\hline $\mathrm{V} 25(\%)$ & $7.9(0.0-24.6)$ & $3.4(0.0-8.6)$ & $14.0(5.6-24.6)$ & $<0.001$ \\
\hline V30 (\%) & $4.6(0.0-14.0)$ & $1.6(0.0-4.7)$ & $8.8(3.5-14.0)$ & $<0.001$ \\
\hline V40 (\%) & $1.5(0.0-6.0)$ & $0.4(0.0-1.4)$ & $2.6(0.8-6.0)$ & $<0.001$ \\
\hline \multicolumn{5}{|l|}{ Ipsilateral lung } \\
\hline MLD (Gy) & $19.2(13.4-21.8)$ & $19.4(13.4-21.8)$ & $19.0(16.7-21.3)$ & 0.521 \\
\hline $\mathrm{V} 5(\%)$ & $96.8(84.3-100.0)$ & $97.9(90.0-100.0)$ & $95.1(84.3-100.0)$ & 0.131 \\
\hline V10 (\%) & $74.1(46.0-94.6)$ & $75.9(46.0-94.6)$ & $71.8(57.1-83.9)$ & 0.349 \\
\hline V20 (\%) & $32.7(21.0-41.3)$ & $33.3(21.0-41.3)$ & $32.0(26.4-38.3)$ & 0.427 \\
\hline V40 (\%) & $11.4(1.4-19.7)$ & $10.9(1.4-15.9)$ & $12.1(8.5-19.7)$ & 0.360 \\
\hline \multicolumn{5}{|l|}{ Contralateral breast } \\
\hline MBD (Gy) & $5.7(2.0-9.5)$ & $5.4(0.0-7.6)$ & $6.1(3.2-9.5)$ & 0.068 \\
\hline $\mathrm{V} 5(\%)$ & $46.7(5.8-10.0)$ & $42.2(5.8-74.1)$ & $52.9(12.2-100.0)$ & 0.177 \\
\hline
\end{tabular}

CI: Confidence interval; MHD: mean heart dose; MLD: mean lung dose; MBD: mean contralateral breast dose.

Table IV. Comparison of dosimetric parameters according to surgery.

\begin{tabular}{|c|c|c|c|c|}
\hline & $\begin{array}{c}\text { All } \\
(\mathrm{n}=31)\end{array}$ & $\begin{array}{c}\text { BCS } \\
(n=13)\end{array}$ & $\begin{array}{c}\text { MRM } \\
(\mathrm{n}=18)\end{array}$ & \\
\hline & & Mean $(95 \%$ CI $)$ & & $p$-Value \\
\hline Homogeneity index & $17.4(9.0-31.6)$ & $16.4(9.0-31.6)$ & $18.1(10.8-31.1)$ & 0.394 \\
\hline Conformity index & $82.5(39.1-98.5)$ & $87.5(75.9-98.5)$ & $78.4(39.1-94.0)$ & 0.062 \\
\hline \multicolumn{5}{|l|}{ Heart } \\
\hline MHD (Gy) & $12.1(5.3-20.3)$ & $11.6(8.6-16.7)$ & $12.6(5.2-20.3)$ & 0.478 \\
\hline $\mathrm{V} 10(\%)$ & $48.6(6.3-98.4)$ & $43.9(22.6-64.4)$ & $52.4(6.3-98.4)$ & 0.274 \\
\hline $\mathrm{V} 20(\%)$ & $13.7(0.0-37.2)$ & $12.2(0.4-31.6)$ & $14.9(0.0-37.2)$ & 0.494 \\
\hline V25 (\%) & $7.9(0.0-24.6)$ & $7.2(0.0-21.1)$ & $8.4(0.0-24.6)$ & 0.650 \\
\hline V30 (\%) & $4.6(0.0-14.0)$ & $4.3(0.0-13.4)$ & $4.8(0.0-14.0)$ & 0.795 \\
\hline V40 (\%) & $1.5(0.0-6.0)$ & $1.3(0.0-6.0)$ & $1.7(0.0-3.9)$ & 0.713 \\
\hline \multicolumn{5}{|l|}{ Ipsilateral lung } \\
\hline MLD (Gy) & $19.2(13.4-21.8)$ & $18.8(13.4-21.7)$ & $19.6(18.2-21.8)$ & 0.236 \\
\hline V5 (\%) & $96.8(84.3-100.0)$ & $96.1(85.8-100.0)$ & $97.3(84.3-100.0)$ & 0.520 \\
\hline V10 (\%) & $74.1(46.0-94.6)$ & $73.3(46.0-92.6)$ & $74.9(63.8-94.6)$ & 0.720 \\
\hline $\mathrm{V} 20(\%)$ & $32.7(21.0-41.3)$ & $31.9(21.0-41.3)$ & $33.4(28.2-37.5)$ & 0.391 \\
\hline V40 (\%) & $11.4(1.4-19.7)$ & $10.4(1.4-15.1)$ & $12.3(6.6-19.7)$ & 0.119 \\
\hline \multicolumn{5}{|l|}{ Contralateral breast } \\
\hline MBD (Gy) & $5.7(2.0-9.5)$ & $6.0(3.9-9.5)$ & $5.4(2.0-8.6)$ & 0.160 \\
\hline $\mathrm{V} 5(\%)$ & $46.7(5.8-10.0)$ & $51.9(14.3-100.0)$ & $42.4(5.8-74.3)$ & 0.226 \\
\hline
\end{tabular}

CI: Confidence interval; BCS: breast-conserving surgery; MRM: modified radical mastectomy; MHD: mean heart dose; MLD: mean lung dose; MBD: mean contralateral breast dose. 
ipsilateral lung 150 days after beginning RT. The median time to development late lung toxicities of any grade was 6.9 months. The incidence of grade 2 acute dermatitis was $19.4 \%$ and severe dermatitis did not develop in any patients. There was no cardiac toxicity observed during the follow-up period.

Local control. No patients experienced locoregional recurrence.

\section{Discussion}

Since VMAT has been used for treatment of breast cancer, many reported the dosimetric outcome of VMAT in comparison to 3-dimensional conformal RT, however, to our knowledge there are no reported clinical results of VMAT, this is the first study reporting the clinical outcomes of VMAT in patients with breast cancer.

Before using VMAT to treat IMN, we had treated patients with locally advanced breast cancer including the IMN with forward intensity-modulated radiation therapy combined with photon-electron (PE-fIMRT) with a field-in-field technique. The weak point of PE-fIMRT was a cold triangle at the matching boundary between the tangential photon beam and the electron beam. If a tumor is in the inner quadrants, the risk of IMN metastasis is higher than for outer tumors (13) and IMN treatment is more likely to be recommended. Ironically, in this situation, the tumor bed would be located in the cold triangle. In addition, patients with IMN metastasis where surgery does not have any role, boost to IMN metastases is needed but it is very difficult to accomplish with great homogeneity and conformity. In order to overcome these problems, VMAT planning has been attempted in our institution since July 2012.

The main concern about the use of VMAT for breast cancer treatment was doses to OAR. In contrast to previous studies, VMAT did not lower OAR doses in our study compared to our previous experience. The main reason for high OAR doses might be the difference in clinical situations. For elective irradiation of IMNs, only the first to third intercostal space levels are included usually, however, in the present study, patients with metastasis of IMN lower than the third intercostal space were not uncommon, hence use of an increasing RT dose to the heart as well as the lungs. In particular, VMAT resulted in a large lung volume receiving a low to moderate RT dose as shown in Tables III and IV.

Nevertheless, radiation toxicities were not remarkable. Contrary to previous results which showed that V5 or V10 are predictors of symptomatic radiation pneumonitis in patients with lung cancer (14-16), only one patient experienced clinically significant pulmonary toxicity despite a high V5 and V10 in our study. We assume that the differences in the patient populations, including performance status and chemotherapy regimen, have produced different consequences. As a result,
Table V. Radiation toxicities $(n=31)$.

\begin{tabular}{lcc}
\hline Toxicity & Acute, $\mathrm{n}(\%)$ & Late, $\mathrm{n}(\%)$ \\
\hline Lung & & \\
Grade 1 & 0 & $10(32.2)$ \\
Grade 2 & 0 & $1(3.2 \%)$ \\
Grade 3-4 & 0 & 0 \\
Skin & & \\
Grade 2 & $6(19 \%)$ & 0 \\
Grade 3-4 & 0 & 0 \\
Heart & 0 & 0 \\
Any grade & 0 & \\
\hline
\end{tabular}

treating IMN with VMAT seems safe in regard to acute and late pulmonary toxicity. No cardiac toxicity has been observed during the follow-up period, however, since RT-induced cardiac toxicities can develop even decades after radiation exposure $(17,18)$, a longer follow-up is mandatory in order to fully evaluate RT-induced cardiac toxicities. Radiation exposure to the contralateral breast can interrupt the treatment of metachronous contralateral breast cancer or generate secondary breast cancer. Considering the incidence of metachronous cancer and the safe outcome after re-irradiation $(19,20)$, and very low possibility of second malignancy after radiation exposure (21), we think benefit from VMAT could outweigh its harm.

The rationale by which we treated patients with locally advanced breast cancer with VMAT, despite the relative high doses to the OAR, was improved homogeneity and conformity of target volumes. In this study, more than half of the patients had gross disease in IMNs or SCNs and the majority of patients had a large number of axillary nodal metastases with tumor located in inner quadrants, suggesting high possibility of developing IMN metastases. Compared to our historical experience of PE-fIMRT, VMAT gave better $\mathrm{HI}$ and CI when treating internal mammary chain with GTV. It is well known that local control is related to overall survival in breast cancer $(22,23)$, therefore efforts to control locoregional disease with an appropriate RT dose is important. Although we cannot conclude whether improved homogeneity and conformity led to better local control and eventually better survival in this study, local control has been excellent so far.

In conclusion, VMAT yielded good homogeneity and conformity when treating IMN in patients with locally advanced breast cancer. High OAR doses did not lead to clinical toxicities and no severe cardiac and lung toxicities were observed at 2 years follow-up. Long-term follow-up is needed to assess the benefit and harm of VMAT and careful patient selection is necessary in choosing VMAT as RT technique. 


\section{References}

1 Lacour J, Bucalossi P, Cacers E, Jacobelli G, Koszarowski T, Le M, Rumeau-Rouquette $\mathrm{C}$ and Veronesi U: Radical mastectomy versus radical mastectomy plus internal mammary dissection. Five-year results of an international cooperative study. Cancer 37: 206-214, 1976.

2 Veronesi U, Marubini E, Mariani L, Valagussa P and Zucali R: The dissection of internal mammary nodes does not improve the survival of breast cancer patients. 30-year results of a randomised trial. Eur J Cancer 35: 1320-1325, 1999.

3 Veronesi U, Arnone P, Veronesi P, Galimberti V, Luini A, Rotmensz N, Botteri E, Ivaldi GB, Leonardi MC, Viale G, Sagona A, Paganelli G, Panzeri R and Orecchia R: The value of radiotherapy on metastatic internal mammary nodes in breast cancer. Results on a large series. Ann Oncol 19: 1553-1560, 2008 .

4 Arthur DW, Arnfield MR, Warwicke LA, Morris MM and Zwicker RD: Internal mammary node coverage: an investigation of presently accepted techniques. Int J Radiat Oncol Biol Phys 48: 139-146, 2000.

5 Otto K: Volumetric modulated arc therapy: IMRT in a single gantry arc. Med Phys 35: 310-317, 2008.

6 Haertl PM, Pohl F, Weidner K, Groeger C, Koelbl O and Dobler B: Treatment of left sided breast cancer for a patient with funnel chest: volumetric-modulated arc therapy vs. 3D-CRT and intensity-modulated radiotherapy. Med Dosim 38: 1-4, 2013.

7 Pasler M, Georg D, Bartelt S and Lutterbach J: Node-positive left-sided breast cancer: does VMAT improve treatment plan quality with respect to IMRT? Strahlenther Onkol 189: 380-386, 2013.

8 Pasler M, Lutterbach J, Bjornsgard M, Reichmann U, Bartelt S and Georg D: VMAT techniques for lymph node-positive left sided breast cancer. Z Med Phys 25: 104-111, 2015.

9 Popescu CC, Olivotto IA, Beckham WA, Ansbacher W, Zavgorodni S, Shaffer R, Wai ES and Otto K: Volumetric modulated arc therapy improves dosimetry and reduces treatment time compared to conventional intensity-modulated radiotherapy for locoregional radiotherapy of left-sided breast cancer and internal mammary nodes. Int J Radiat Oncol Biol Phys 76: 287-295, 2010.

10 Sakumi A, Shiraishi K, Onoe T, Yamamoto K, Haga A, Yoda K, Ohtomo K and Nakagawa K: Single-arc volumetric modulated arc therapy planning for left breast cancer and regional nodes. J Radiat Res 53: 151-153, 2012.

11 Viren T, Heikkila J, Myllyoja K, Koskela K, Lahtinen T and Seppala J: Tangential volumetric modulated arc therapy technique for left-sided breast cancer radiotherapy. Radiat Oncol 10: 79, 2015.

12 Gagliardi G, Constine LS, Moiseenko V, Correa C, Pierce LJ, Allen AM and Marks LB: Radiation dose-volume effects in the heart. Int J Radiat Oncol Biol Phys 76: S77-85, 2010.
13 Huang O, Wang L, Shen K, Lin H, Hu Z, Liu G, Wu J, Lu J, Shao Z, Han Q and Shen Z: Breast cancer subpopulation with high risk of internal mammary lymph nodes metastasis: analysis of 2,269 Chinese breast cancer patients treated with extended radical mastectomy. Breast Cancer Res Treat 107: 379-387, 2008.

14 Ferrero C, Badellino S, Filippi AR, Focaraccio L, Giaj Levra M, Levis M, Moretto F, Torchio R, Ricardi $U$ and Novello S: Pulmonary function and quality of life after VMAT-based stereotactic ablative radiotherapy for early-stage inoperable NSCLC: a prospective study. Lung Cancer 89: 350-356, 2015.

$15 \mathrm{Kim}$ Y, Hong SE, Kong M and Choi J: Predictive factors for radiation pneumonitis in lung cancer treated with helical tomotherapy. Cancer Res Treat 45: 295-302, 2013.

16 Bongers EM, Botticella A, Palma DA, Haasbeek CJ, Warner A, Verbakel WF, Slotman B, Ricardi U and Senan S: Predictive parameters of symptomatic radiation pneumonitis following stereotactic or hypofractionated radiotherapy delivered using volumetric modulated arcs. Radiother Oncol 109: 95-99, 2013.

17 Darby SC, Ewertz M, McGale P, Bennet AM, Blom-Goldman U, Bronnum D, Correa C, Cutter D, Gagliardi G, Gigante B, Jensen B, Nisbet A, Peto R, Rahimi K, Taylor C and Hall P: Risk of ischemic heart disease in women after radiotherapy for breast cancer. N Engl J Med 368: 987-998, 2013.

18 Darby SC, McGale P, Taylor CW and Peto R: Long-term mortality from heart disease and lung cancer after radiotherapy for early breast cancer: prospective cohort study of about 300,000 women in US SEER cancer registries. Lancet Oncol 6: 557-565, 2005.

19 Hartman M, Czene K, Reilly M, Adolfsson J, Bergh J, Adami HO, Dickman PW and Hall P: Incidence and prognosis of synchronous and metachronous bilateral breast cancer. J Clin Oncol 25: 4210-4216, 2007.

20 Wurschmidt F, Dahle J, Petersen C, Wenzel C, Kretschmer M and Bastian C: Reirradiation of recurrent breast cancer with and without concurrent chemotherapy. Radiat Oncol 3: 28, 2008.

21 Boice JD Jr., Harvey EB, Blettner M, Stovall M and Flannery JT: Cancer in the contralateral breast after radiotherapy for breast cancer. N Engl J Med 326: 781-785, 1992.

22 Clarke M, Collins R, Darby S, Davies C, Elphinstone P, Evans V, Godwin J, Gray R, Hicks C, James S, MacKinnon E, McGale $\mathrm{P}$, McHugh T, Peto R, Taylor $\mathrm{C}$ and Wang Y: Effects of radiotherapy and of differences in the extent of surgery for early breast cancer on local recurrence and 15-year survival: an overview of the randomised trials. Lancet 366: 2087-2106, 2005.

23 Whelan TJ, Julian J, Wright J, Jadad AR and Levine ML: Does locoregional radiation therapy improve survival in breast cancer? A meta-analysis. J Clin Oncol 18: 1220-1229, 2000.

Received July 12, 2016

Revised July 31, 2016

Accepted August 1, 2016 